\title{
Angiographic and electrophysiological substrates for ventricular tachycardia mapping through the coronary veins
}

\author{
Angelo A V de Paola, Wesley D S Melo, Maria Z P Távora, Eulogio E Martinez
}

\begin{abstract}
Objective-To study the value of epicardial mapping through the coronary venous system in patients with sustained ventricular tachycardia.

Design-20 consecutive patients with sustained ventricular tachycardia who were candidates for radiofrequency ablation.

Setting-Electrophysiological laboratory. Interventions-Coronary venous angiography was performed with a catheter, which provided coronary sinus occlusion during injection of contrast media. Multipolar microelectrode catheters were then manoeuvred into the tributaries of coronary sinus, using an over-wire system or an on-wire system. An endocardial ablation catheter was positioned in the left ventricle. Conventional programmed ventricular stimulation was performed for sustained ventricular tachycardia induction. Endocardial radiofrequency ablation was performed using impedance or temperature monitoring.

Results-Coronary veins were catheterised in all patients; 20 had induction of sustained ventricular tachycardia, 14 were stable. Presystolic epicardial electrograms were recorded in six patients and concealed entrainment in two, helping as a landmark for endocardial ablation. After simultaneous epicardial and endocardial mapping, successful endocardial radiofrequency ablation was achieved in nine of 14 patients with stable ventricular tachycardia (64\%).

Conclusions-Epicardial mapping through the coronary veins in patients with ventricular tachycardia is feasible, safe, and can be a useful landmark for endocardial catheter mapping and ablation.

(Heart 1998;79:59-63)
\end{abstract}

Keywords: ventricular tachycardia; coronary angiography; cardiac mapping; radiofrequency ablation

Electrophysiology

Section, Cardiology

Division, Paulista

School of Medicine,

Federal University of

S Paulo, Brazil

Correspondence to:

Dr Angelo A V de Paola, Clinical Cardiac

Electrophysiology, Paulista School of Medicine, Rua: Napoleão de Barros 593, CEP: 04024-002, S Paulo, Brazil.

Accepted for publication 1 September 1997

tachycardia, at least a portion of the reent circuit involves the subendocardium. ${ }^{1}$ Endocardial catheter mapping techniques have mainly been used in clinical practice and are responsible for our current understanding about the mechanisms and sites of origin of ventricular tachycardia. ${ }^{2}$ However, intramyocardial and epicardial regions of slow conduction can be critical components of reentry circuits, ${ }^{34}$ and might be better defined by epi- cardial mapping than by conventional intracavitary mapping techniques. The coronary venous system is a complex network with many anastomoses ${ }^{5}$ but only the coronary sinus has been used for diagnostic and therapeutic interventions. ${ }^{6-9}$ Detailed studies of coronary venous angiography have not been reported, though they could provide important background information for epicardial mapping through the venous system of the heart.

The aim of this paper is to describe the anatomy of the venous system of the heart, and to evaluate microelectrode catheter techniques using the coronary veins for electrophysiological epicardial mapping in patients with sustained ventricular tachycardia.

\section{Methods}

PATIENTS

Twenty consecutive patients with sustained clinical ventricular tachycardia were admitted to the clinical cardiac electrophysiology section of Paulista School of Medicine, Federal University of Sao Paulo, and included in the present investigation. There were $17 \mathrm{men}$ and three women, ages ranging from 35 to 76 years. Five patients had a history of myocardial infarction, three had idiopathic ventricular tachycardia, and 12 had dilated cardiomyopathy (nine of chagasic aetiology). All patients had Holter monitoring, electrophysiological studies, and coronary and left ventricular angiography.

ANGIOGRAPHIC CATHETER PLACEMENT

After written informed consent had been obtained, coronary venous angiography was performed through the right internal jugular vein using a $7 \mathrm{~F}$ occlusion catheter with a balloon located $10 \mathrm{~mm}$ from the tip to provide coronary sinus occlusion (Electro-Catheter Corporation, Rahway, New Jersey, USA) and consequently better visualisation of the venous system during injection of contrast media. ${ }^{10}$ After balloon inflation with $1.5 \mathrm{ml}$ room air, $5-10 \mathrm{ml}$ of contrast was delivered in the distal and proximal segments of the coronary sinus. Angiography was recorded in right anterior oblique $\left(30^{\circ}\right)$ and left anterior oblique $\left(45^{\circ}\right)$ projections.

\section{ANGIOGRAPHIC ANALYSIS}

Angiographic analysis was performed through automated detection of the venous contours, using the Cardiovascular Measurement System, version 3.0 (Medical Imaging Systems, Neunen, the Netherlands). The 7 F coronary 


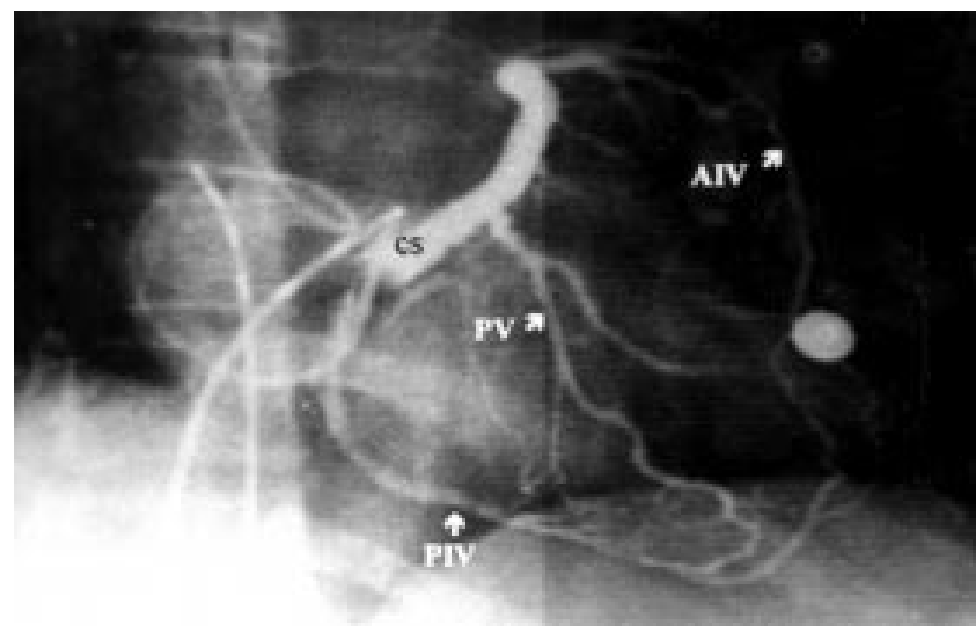

Figure 1 Right anterior oblique coronary venous angiography performed with coronary sinus occlusion technique. Coronary vein anastomoses are clearly seen in this patient. AIV, anterior interventricular vein; CS, coronary sinus; PIV, posterior interventricular vein; $P V$, left posterior vein. speeds of 100 and $200 \mathrm{~mm} / \mathrm{s}$. After induction of clinical sustained ventricular tachycardia (similar to the documented spontaneous arrhythmia), bipolar microelectrode epicardial mapping was obtained from the interventricular anterior vein, left ventricular posterior vein, and interventricular posterior vein. If epicardial or endocardial presystolic activation was recorded during ventricular tachycardia, pacing with stimuli twice the diastolic threshold and $2 \mathrm{~ms}$ in duration was performed at these sites, starting at cycle lengths of 20 to $40 \mathrm{~ms}$ shorter than the ventricular tachycardia cycle length and decreasing by $20 \mathrm{~ms}$ until the ventricular tachycardia was entrained. ${ }^{2}$ If presystolic activation, fragmentation, or concealed entrainment were obtained from one of these veins during epicardial mapping, this position was subsequently used as a landmark during endocardial catheter mapping and ablation. Success of radiofrequency (RF) ablation was defined as termination and non-inducibility of sustained ventricular tachycardia after endocardial RF application.

During mapping, intravenous heparin 5000 IU was given as a bolus, followed by $1000 \mathrm{IU} / \mathrm{h}$ as an infusion, which was maintained to the end of the procedure.

\section{STATISTICAL ANALYSIS}

Results are presented as mean (SD). Statistical comparisons were made using analysis of variance, Wilcoxon, and Tukey tests. Significance was defined as $\mathrm{p}<0.05$.

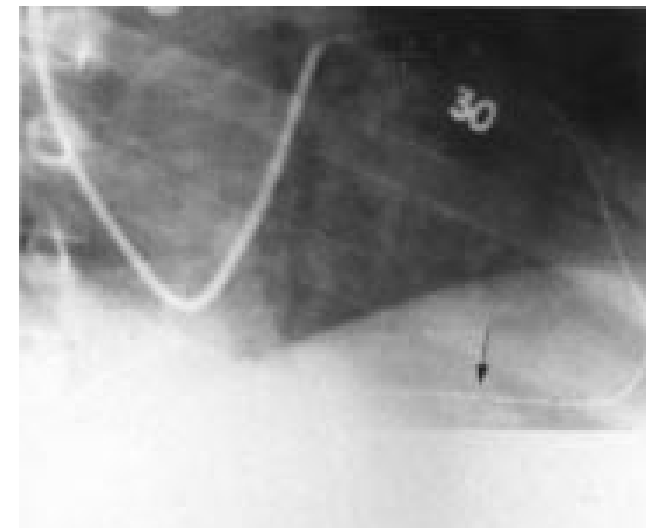
physiology LabSystem version 2.56 or TEB-SP 12 (Tecnologia Eletronica Brasileira), at paper

Table 1 Angiographic anastomosis of coronary veins

\begin{tabular}{ccccc}
\hline$A I V-P I V$ & $P I V-L M$ & $P I V-P V$ & $A I V-L M$ & $A I V-P V$ \\
\hline $19 / 20$ & $2 / 20$ & $11 / 20$ & $3 / 20$ & $9 / 20$ \\
$(95 \%)$ & $(10 \%)$ & $(55 \%)$ & $(15 \%)$ & $(45 \%)$ \\
\hline
\end{tabular}

AIV, anterior interventricular vein; LM, left marginal vein; PIV posterior interventricular vein; $\mathrm{PV}$, left posterior ventricular vein.

Table 2 Left ventricular vein diameter

\begin{tabular}{llll}
\hline & Distal calibre & Mid-calibre & Proximal calibre \\
\hline AIV & $1.11(0.20) \mathrm{mm}$ & $1.69(0.29) \mathrm{mm}$ & $2.82(0.79) \mathrm{mm}$ \\
PIV & $1.85(0.56) \mathrm{mm}^{\star}$ & $2.10(0.60) \mathrm{mm}^{\star}$ & $3.20(1.09) \mathrm{mm}$ \\
PV & $1.45(0.27) \mathrm{mm}^{\star}$ & $2.40(0.56) \mathrm{mm}^{\star}$ & $3.24(0.81) \mathrm{mm}$
\end{tabular}

Values are means (SD).

${ }^{\star} \mathrm{p}<0.05 v$ AIV.

AIV, anterior interventricular vein; PIV, posterior interventricular vein; PV, left posterior ventricular vein.

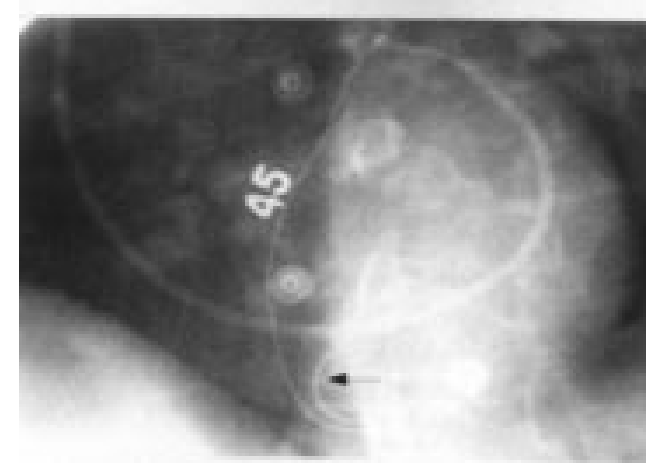

Figure 2 Coronary venous angiography with anastomosis connecting the anterior interventricular vein with the posterior interventricular vein. Mapping of the anterior and posterior walls of the left ventricle was possible using a single microelectrode catheter. This patient had severe coronary artery narrowings but normal coronary veins. Top, $30^{\circ}$ right anterior oblique; bottom, $45^{\circ}$ left anterior oblique. 

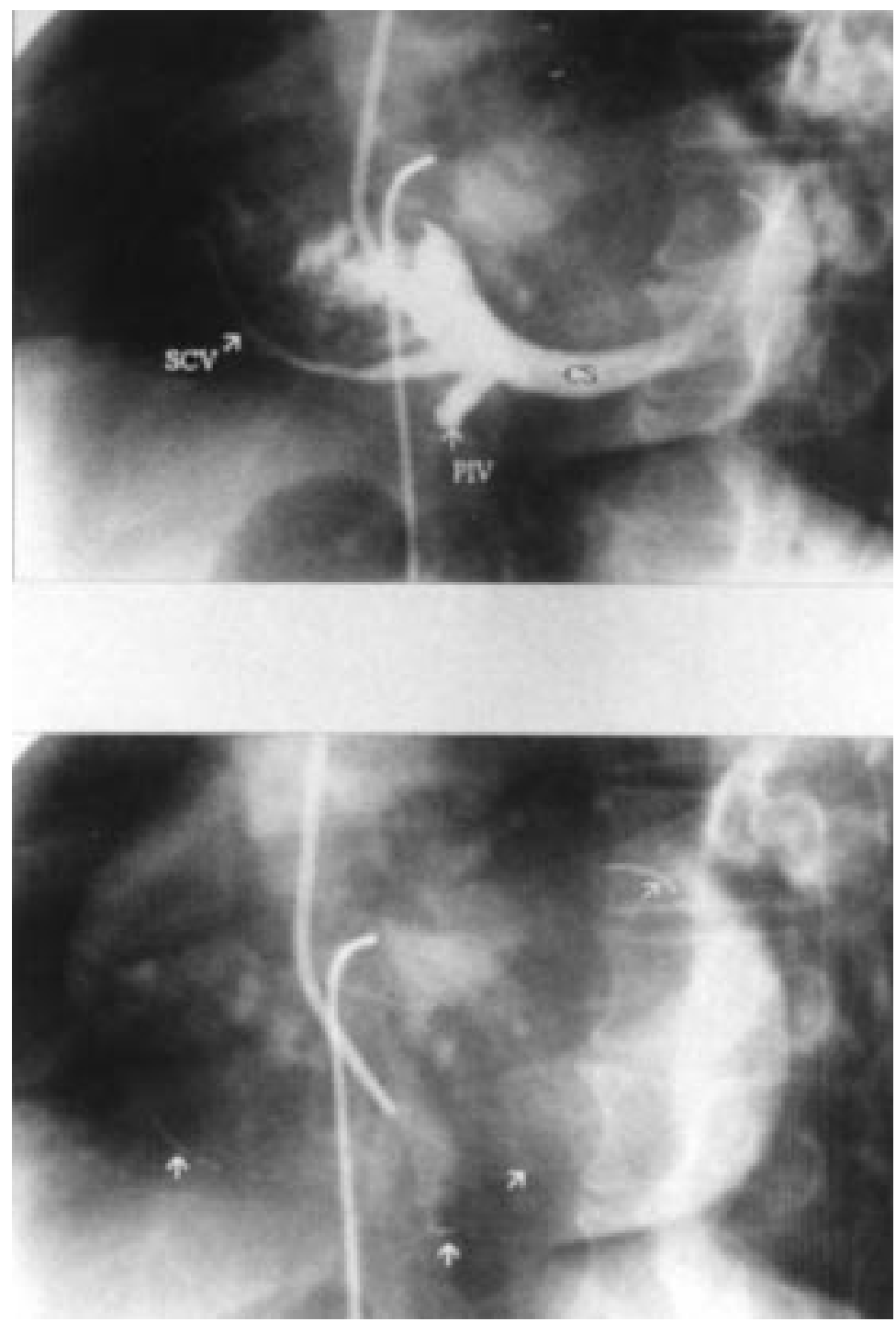

Figure 3 Top: Left anterior oblique coronary venous angiography in a patient showing the coronary sinus (CS), small cardiac vein (SCV), and posterior interventricular vein (PIV). Bottom: Microelectrode catheters positioned in the same veins (arrows) for simultaneous recording during epicardial mapping.

\section{Results}

CORONARY VENOUS ANGIOGRAPHY

The coronary veins were studied according to their number, calibre, and distribution in the anterior and posterior wall of the left ventricle. Angiographic anastomosis was a common finding (table 1), connecting the anterior interventricular vein, the left marginal vein, the posterior interventricular vein, and the left posterior vein (fig 1). The veins of the posterior wall of the left ventricle had a significantly greater calibre in the mid and distal portions than those of the anterior wall (table 2). Potentially cannulated veins (mid-portion calibre $>1.3 \mathrm{~mm}$ ) were also significantly more frequent in the posterior wall (median 3.1 veins) than in the anterior wall (median 1.9 veins). Coronary venous narrowings were not observed (fig 2).

CORONARY VEIN CATHETERISATION AND MAPPING Twenty seven veins were catheterised by microelectrode catheters for epicardial mapping during induced sustained ventricular tachycardia. Epicardial mapping was performed with one microelectrode catheter in 14 patients (fig 3) and with multiple catheters in six; epicardial mapping with simultaneous recording using two veins was obtained in five patients and with three veins in one patient. Angiographic anastomosis were used for catheterisation of two veins with the same catheter in four patients.

\section{PROGRAMMED VENTRICULAR STIMULATION}

Conventional programmed right ventricular stimulation induced sustained ventricular tachycardia in all patients. Mean (SD) cycle length of ventricular tachycardia was 334 (62) ms. Mapping was possible in only 14 patients; in six patients ventricular tachycardia was unstable despite the use of procainamide, and required termination of the ventricular tachycardia, so mapping could not be performed.

\section{EPICARDIAL MAPPING}

After induction of sustained ventricular tachycardia, presystolic activation, pace mapping, and concealed entrainment were used by epicardial and endocardial recordings to identify the site of the origin of ventricular tachycardia. During epicardial mapping presystolic activation was obtained in six patients (ranging from 30 to $80 \mathrm{~ms}$ ) and concealed entrainment in two (fig 4).

\section{ENDOCARDIAL MAPPING AND RADIOFREQUENCY} ABLATION

An $8 \mathrm{~mm}$ tip catheter was used for endocardial mapping and ablation during induced sustained ventricular tachycardia. Localisation of the site of the origin of ventricular tachycardia was initially done using epicardial signals as

Table 3 Clinical and electrophysiological characteristics of patients with sustained ventricular tachycardia during epicardial mapping

\begin{tabular}{|c|c|c|c|c|c|c|}
\hline Patient & $\begin{array}{l}\text { Age } \\
\text { (years) }\end{array}$ & Aetiology & Vessel & $\begin{array}{l}\text { Epic- } \\
P S A \\
\text { (ms) }\end{array}$ & $\begin{array}{l}\text { Epic- } \\
C E\end{array}$ & $\begin{array}{l}\text { Endoc- } \\
\text { RF } \\
\text { success }\end{array}$ \\
\hline 1 & 62 & Chagas & PV & - & - & + \\
\hline 2 & 58 & Chagas & PV & 30 & - & + \\
\hline 3 & 65 & MI-Inf & PV & 40 & - & - \\
\hline 4 & 59 & CMP & IAV/PIV & 30 & - & - \\
\hline 5 & 59 & ILVT & AIV & - & - & + \\
\hline 6 & 42 & CMP & $\mathrm{PV}(2)$ & - & - & - \\
\hline 7 & 55 & Chagas & PV & 80 & + & + \\
\hline 8 & 71 & MI-Ant & AIV & - & - & - \\
\hline 9 & 52 & MI-Inf & $\mathrm{PV}(2)$ & 40 & + & + \\
\hline 10 & 76 & RVOT & AIV & - & - & + \\
\hline 11 & 35 & Chagas & PIV & - & - & - \\
\hline 12 & 29 & $\mathrm{CMP}$ & AIV/PIV & - & - & - \\
\hline 13 & 42 & Chagas & PV & - & - & + \\
\hline 14 & 47 & Chagas & $\mathrm{PV}(2)$ & - & - & - \\
\hline 15 & 62 & Chagas & AIV & - & - & - \\
\hline 16 & 71 & MI-Ant & $\begin{array}{l}\text { AIV/PIV/ } \\
\text { SCV }\end{array}$ & - & - & - \\
\hline 17 & 52 & Chagas & PV & - & - & + \\
\hline 18 & 45 & ILVT & AIV & - & - & - \\
\hline 19 & 71 & MI-Inf & AIV & - & - & - \\
\hline 20 & 46 & Chagas & PV & 80 & - & + \\
\hline
\end{tabular}

AIV, anterior interventricular vein; Ant, anterior; CMP, cardiomyopathy; Endoc-RF success, successful endocardial radiofrequency ablation; Epic-CE, epicardial concealed entrainment; Epic-PSA, epicardial presystolic activation; ILVT, idiopathic left ventricular tachycardia; Inf, inferior; MI, myocardial infarction; $\mathrm{PIV}$, posterior interventricular vein; PV, left posterior ventricular vein; RVOT, right ventricular outflow tract tachycardia; SCV, small cardiac vein; (2), cannulation of two left ventricular posterior veins. 
A

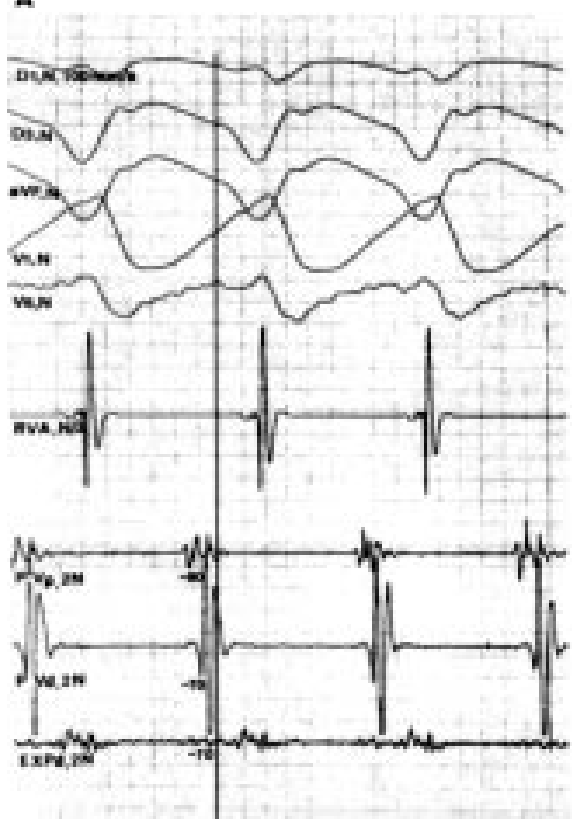

B

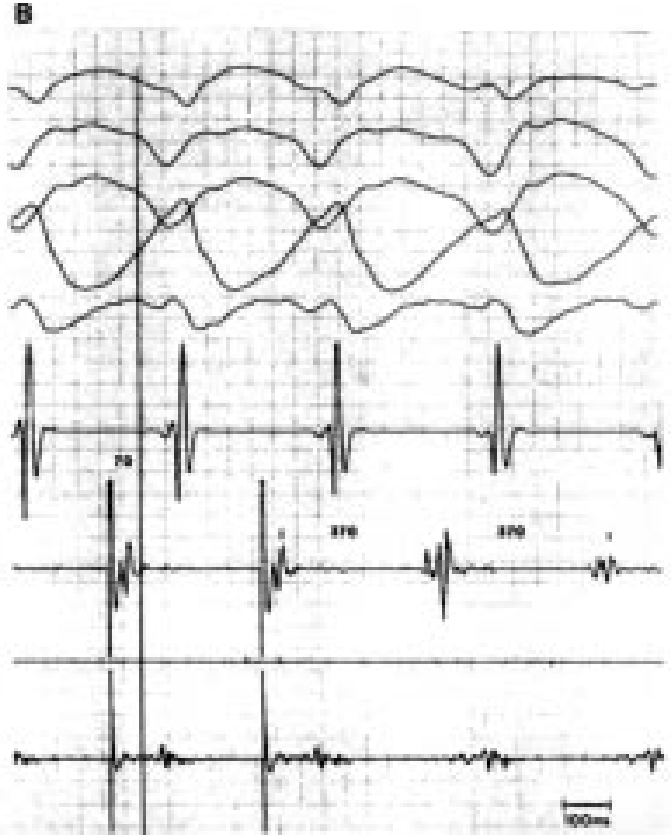

Figure 4 Coronary venous mapping during ventricular tachycardia. Five surface ECG leads and electrograms from the right ventricle $(R V)$, proximal posterior vein $(P V p)$, distal posterior vein $(P V d)$, and left ventricular endocardial ablation catheter (EXP). (A) During sustained ventricular tachycardia, presystolic activation was recorded simultaneously from the epicardial (PVp and PVd) and endocardial (EXP) electrode catheters. (B) Epicardial pacing from PVd electrode pair: concealed entrainment of ventricular tachycardia with stimulus to QRS interval (70 ms) similar to presystolic activation and return cycle (370 ms) equal to ventricular tachycardia cycle length.

landmarks in the six patients who had presystolic activity during epicardial mapping. In two of these patients, concealed entrainment was also obtained from the distal pair of electrodes of the epicardial catheter; these landmarks were of the utmost importance for positioning the endocardial catheter for mapping and ablation (fig 5). After simultaneous epicardial and endocardial mapping, successful endocardial radiofrequency ablation using impedance or temperature monitoring was achieved in nine of 14 mappable patients (table 3).

\section{Discussion}

Studies in patients with myocardial infarction and ventricular tachycardia support the prime importance of the endocardium in the initiation of this arrhythmia. However, animal and human experiments have shown a variety of reentrant circuit configurations, suggesting that intramural and epicardial reentry may also be critical in the genesis and maintenance of ventricular tachycardia.

Radiofrequency catheter ablation of supraventricular tachycardia has success rates of 95-100\%. These rates are greater than those obtained in patients with sustained ventricular tachycardia, especially when associated with organic heart disease. A non-critical role of the endocardium in such tachycardias, and macroreentrant circuits involving the intramural or epicardial layers, can explain some of the failures that have occurred when endocardial techniques have exclusively been used for mapping and ablation.

There are few reports of intravascular epicardial approaches for the diagnosis and treatment of cardiac arrhythmias. They have used the coronary arteries for mapping right cardiac pathways or performing chemical ablation of cardiac arrhythmias. ${ }^{11-13}$ Atherosclerosis, dissection, and spasm of coronary arteries are important limitations of this technique.

The coronary venous system could be an attractive option for intravascular epicardial mapping of ventricular tachycardia. The use of the balloon occlusion technique was very important in our study. Clear visualisation of coronary veins was achieved in all patients and their anatomy was not affected by underlying heart disease. Coronary veins were significantly more numerous and larger in the posterior wall of the left ventricle; these data are very important when considering mapping or epicardial interventions in this area. For purposes of catheterisation and manoeuvrability, we analysed veins with a mid-portion calibre greater than $1.3 \mathrm{~mm}(4.0 \mathrm{~F})$ in this study. The diameter of the microelectrode catheters available in our study varied from $1.8 \mathrm{~F}$ to $3.4 \mathrm{~F}$.

Selective catheterisation with microelectrode catheters was technically simple, causing no discomfort and based on our preliminary experience two catheters can be introduced easily in the majority of patients. In two of our patients $(10 \%)$ who had previously undergone unsuccessful endocardial mapping, the epicardial intravascular technique was important not only for mapping but also for guiding radiofrequency endocardial catheter ablation. These patients probably had macroreentrant circuits: epicardial concealed entrainment and successful endocardial radiofrequency ablation were obtained in the same patients, in the posterior wall of the left ventricle. 


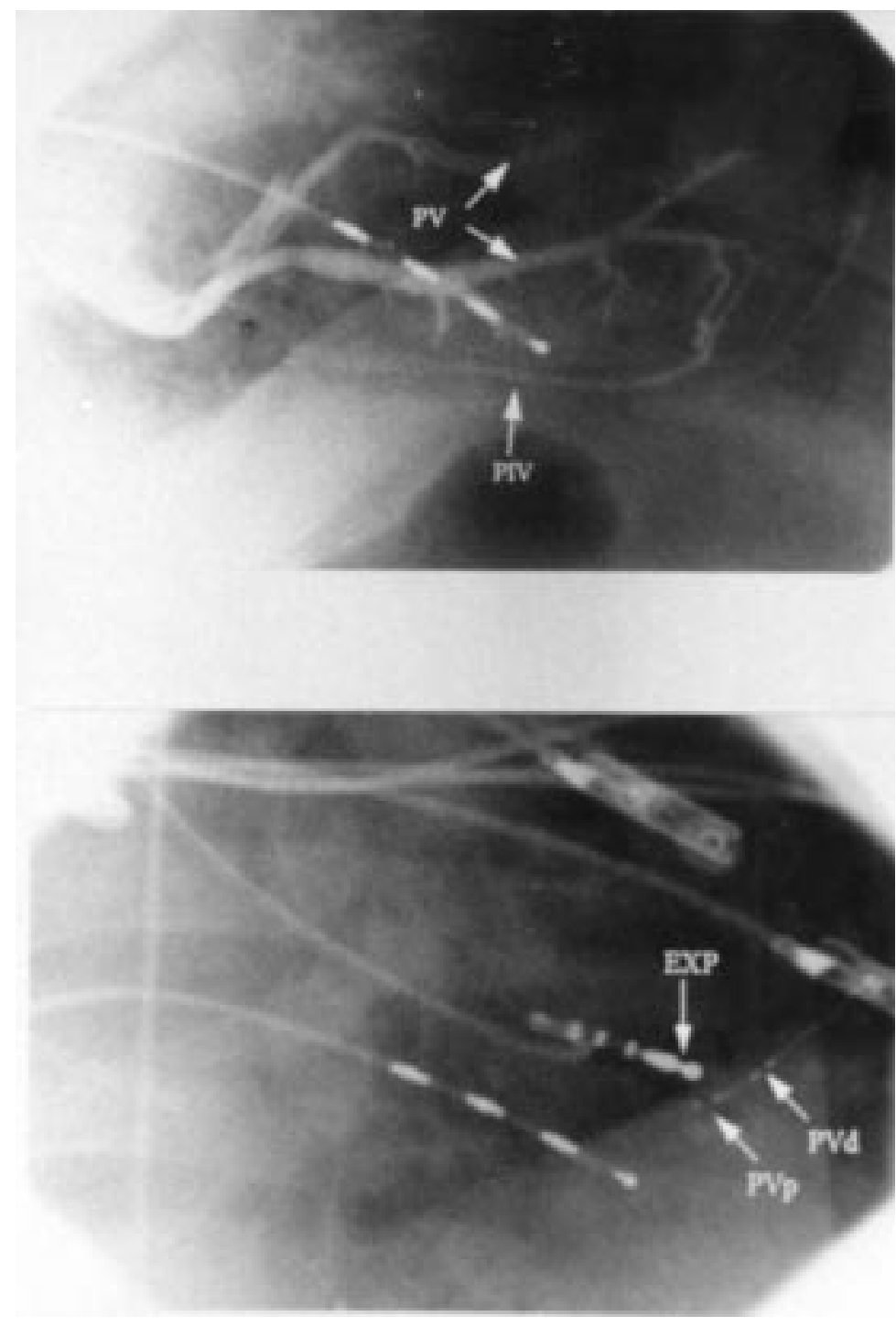

Figure 5 The same patient as in fig 4. Top: Right anterior oblique angiography showing anastomosis of the left posterior veins (PV) and posterior interventricular vein (PIV) in the posterior wall of the left ventricle. Bottom: Selective catheterisation of the left posterior vein showing the distal (Pvd) and proximal (Pvp) pair of electrodes where concealed entrainment was obtained. These intravascular epicardial electrodes guided an $8 \mathrm{~mm}$ endocardial catheter (EXP) for a successful radiofrequency ablation.

\section{MAPPING LIMITATIONS}

The precise localisation of the critical components of a reentry circuit may be identified by epicardial mapping when one or more veins are adjacent to the site of the origin of ventricular tachycardia. The venous system of the posterior wall of the left ventricle offers a greater chance of mapping success, but not all the veins are suitable for selective cannulation. Miniature catheters and new mapping techniques ${ }^{14}$ may contribute to mapping large epicardial areas.
Catheter ablation of ventricular tachycardia is technically challenging. Intravascular epicardial techniques performed through the coronary venous system are feasible and safe, but further studies are required to determine the value of this new technique in patients with ventricular arrhythmias. It may be useful in providing landmarks for endocardial catheter mapping and ablation, especially when the site of ventricular tachycardia is located in the posterior wall of left ventricle. Finally, epicardial mapping may also identify intramural and subepicardial circuits where special new techniques, including epicardial ablation, should be considered in the future.

This study was supported in part by CNPQ (Conselho Nacional de Desenvolvimento Científico e Tecnológico), S Paulo, Brazil.

1 Josephson ME, Horowitz LN, Farshidi A, Spear JF, Kastor JA, Moore N. Recurrent sustained ventricular tachycardia. Endocardial mapping. Circulation 1978;57:440-7.

2 Stevenson WG, Khan H, Sager P, Saxon LA, Middlekauff HR, Natterson PD, et al. Identification of reentry circuit sites during catheter mapping and radiofrequency ablation of ventricular tachycardia late after myocardial infarction. Circulation 1993;88:1647-70.

3 Kaltenbrunner W, Cardinal R, Dubuc M, Shenasa M, Nadeau R, Tremblay G, et al. Epicardial and endocardial mapping of ventricular tachycardia in patients with myocardial infarction. Circulation 1991;84:1058-71

4 Svenson RH, Littmann L, Gallagher JJ, Selle JG, Zimmern $\mathrm{SH}$, Fedor JM, et al. Termination of ventricular tachycardia with epicardial laser photocoagulation: a clinical comparison with patients undergoing successful endocardial photocoagulation alone. 7 Am Coll Cardiol 1990;15:163photo

5 Gregg DE, Saipley RE. Studies of venous drainage of the heart. Am f Physiol 1947;151:13-25.

6 Gore JM, Weiner BH, Benotti JR, Sloan KM, Okike ON, Cuénoud $\mathrm{HF}$, et al. Preliminary experience with synchronized coronary sinus retroperfusion in humans. Circulation 1986;74:381-8.

7 Meerbaum S, Lang T, Povzhitkov M, Haendchen RV, Uchiyama T, Broffman J, et al. Retrograde lysis of coronary artery thrombus by coronary venous streptokinase administration. F Am Coll Cardiol 1983;1:1262-7.

8 Magorien RD, Frederick J, Leier CV, Unverferth DH. Influence of exercise on coronary sinus blood flow determinations. Am f Cardiol 1987;59:659-61.

9 Haissaguerre M, Gaita F, Fischer B, Egloff P, Lemetayer P, Warin J. Radiofrequency catheter ablation of left lateral accessory pathways via the coronary sinus. Circulation 1992;86:1464-8.

10 Arruda M, Otomo K, Tondo C, McClelland J, Beckman K, Nakagawa $\mathrm{H}$, et al. Coronary sinus angiography using an "occlusion" technique as an aid to radiofrequency ablation of epicardial accessory pathways [abstract]. PACE 1995;18: 833.

11 De Paola AAV, Gomes JA, Miyamoto MH, Martinez EE. Transcoronary chemical ablation of ventricular tachycardia in chronic chagasic cardiomyopathy. $f \mathrm{Am}$ Coll Cardiol 1992;20:480-2

12 De Paola AAV, Horowitz LN, Vattimo AC, Marques FBR, Myamoto MH, Ferreira DF, et al. Sinus node artery occlusion for treatment of chronic nonparoxysmal sinus tachycardia. Am 7 Cardiol 1992;70:128-30.

13 Brugada P, de Swart H, Smeets JLRM, Wellens HJJ. Transcoronary chemical ablation of ventricular tachycardia. Circulation 1989;79:475-82

14 Sosa E, Scanavacca M, D'Avila A, Pilleggi F. A new technique to perform epicardial mapping in the electrophysiology laboratory. f Cardiovasc Electrophysiol 1996;7: $531-6$. 